\title{
Morality and Tribalism
}

\section{Debating Buchanan's "Our Moral Fate"}

\section{Claudio Corradetti ${ }^{1}$}

Accepted: 12 March 2021/Published online: 4 May 2021

(c) The Author(s) 2021

\begin{abstract}
This contribution has two main goals which might be labelled for convenience as a pars construens and pars denstruens reversing the usual order of these terms. The first aim is to offer an overview of the main tenets of the book, while the second aim is to raise some critical concerns while remaining sympathetic to the author's overall project. With regard to the first point, I present the context of intellectual debate where Buchanan's contribution fits comfortably: Darwin's evolutionary theory, anthropology, psychology, moral analysis etc. The target here is to show the internal complexity and different layers of analysis of the book. These initial reconstructions are, next, used to formulate some thoughts on what I consider possible problematic points in need of clarification. In particular, first, I hold that Buchanan presents too narrow oppositional views between intergroup relations whereupon the notion of "tribalism" is constructed. Such strong identitarian conception does not seem to depict adequately the sociological dynamics of intergroup relations. Second, I consider the terms in which it can be addressed the notion of the rise of the moral mind in evolutionary terms. The suggestion is to consider in a milder form the author's key concept of a "Great Uncoupling" for the moral reason.
\end{abstract}

Keywords Evolutionary theory $\cdot$ Morality $\cdot$ Buchanan

\section{Introduction}

Buchanan's book Our Moral Fate. Evolution and the Escape from Tribalism, ${ }^{1}$ is a challenging and thought-provoking work. Perhaps the first and most important feature is that it looks at morality through evolutionary theory. ${ }^{2}$ Is morality innate or

\footnotetext{
1 Buchanan (2020).

2 Buchanan defines evolutions as "descent with modification", Buchanan (2020), 70.

Claudio Corradetti

Claudio.Corradetti@uniroma2.it

1 University of Rome Tor Vergata, Rome, Italy
} 
not? Can it receive an exclusive adaptive genetic account? Alternatively, shall we give any credit to the (Lockean) idea of the mind as a tabula rasa? ${ }^{3}$

Buchanan wants to recognize a role to evolutionary psychology but he does not aim to be a biological innatist or determinist in the way in which one might consider, respectively, i.e. Richards and Campbell theory on innate morality ${ }^{4}$ or Dawkins's theory of the Selfish Gene. ${ }^{5}$ Nor for Buchanan an evolutionary approach to moral reason is to be confused with hyper functionalism (the idea that everything has a function that develops in accordance to reproductive fitness). The result is that "morality is not constituted by any biological or social function", 6 even when it absolves "a functional "social technology", widespread in various human ecologies.

For Buchanan, biology played a fundamental role until the moral mind emerged. Thus, it bears no deterministic relation between these two fields. Certainly, it is the case that some pro-social behaviours are genetically hard-wired: think of various natural forms of altruism, helping behaviour or fitness sacrificing. ${ }^{8}$ Yet, these natural determinations provide a limited account for our cooperative behaviour, particularly if one considers the role of cultural accumulation and large-scale moral change. Given that in modern homo sapiens moral psychology has remained the same, what is to be explained is its capacity for niche construction and moral change. ${ }^{9}$

Buchanan's normative characterization of the practical mind aims at combining both naturalism and constructivism in morality. This results in a problematic matching between a natural cognitivist and a constructivist idea of the moral truth, but it certainly avoids a violation of Hume's law and the deduction of an "ought" from an "is". Indeed, the merit of Buchanan's moral evolutionary theory is, to start with, avoidance of reduction of the moral truth to social-functionalist considerations. This explains the constructivist role of cultural niches for normative-practical codes.

Buchanan's theory also takes a careful distance from standard cultural evolutionist theories which consider moral progress as mere unreflective transmissions of social practices. The uniquely human capacity to practice normative reflectionwhat Buchanan and Powell name "open-ended normativity" $\_{ }^{10}$ is a radically different capacity from what anthropologist call the replication and transmission of social practices. This capacity explains why "an evolutionary account of moral

\footnotetext{
3 Joyce (2006), 2. "i) Evolutionary psychology does not claim that observable human behavior is adaptive, but rather that it is produced by psychological mechanisms that are adaptations. The output of an adaptation need not be adaptive". In, Joyce (2006), 5.

4 Richards (1986) and Campbell (1996).

5 This work had an extraordinary success and three editions, the latest of which is Dawkins (2016).

6 Buchanan and Powell (2018), 387.

7 Ibid.

8 Joyce (2006), $13 \mathrm{ff}$.

9 "the ability to create new environments in which we are subject to new pressures for natural selection and in which different potential moralities can be realized", Buchanan (2020), 49.

${ }^{10}$ Buchanan and Powell (2018), 397.
} 
psychological development [...] can accommodate the inclusivist anomaly [of an inclusivist morality]". ${ }^{11}$ What might be regarded as a natural exception in pre-cultural settings becomes a moral code in adaptations of cultural niches. For Buchanan, this testifies of the "adaptively plastic" 12 character of the moral mind, one that shows plasticity and inclusive adaptation when facing favourable conditions of reproduction. As Buchanan and Powell vividly put this point:

Morality, on this view, is more like the water flea's armor- a conditionally expressed trait whose development depends on the presence or absence of predatory threat cues in the environment - than it is like either the moth's proboscis (a standard adaptation), the peacock's tail (an adaptation resulting from sexual selection), or the spotted hyena's large clitoris (a by-product of selection). (Buchanan and Powell 2018, 377)

There are precise conditions that can be identified for the rise of our moral capacities. Once humans modified their hostile environments, reaching more pleasant conditions of living as in the Neolithic agrarian revolution, morality came to regulate processes of socialization. These newly emerged conditions favoured also the formation of institutions, cultural groups, social rankings as well as a rough division of labour and social roles. Political authority was necessary to rule large social groups and the types of group moralities that accompanied these phases developed through a separation between an in-out member affiliation, thus, justifying aggressive external behaviour. ${ }^{13}$ But this is only part of the whole story.

The natural account of the birth of morality has also undergone moral progress more recently - in the last 300 years-with what Buchanan calls as the Two Great Expansions: the invention of human rights and the recognition of the moral worthiness of animals. These two events have led to the decoupling of morality from reproductive fitness.

In the following comments, I first present Buchanan's view in Our Moral Fate (2020) and then discuss it critically by considering possible interlinks between evolutionary theory and cognitive and moral development.

Buchanan's book is very accessible and pleasant to read, but it must be handled with care. The levels of analysis involved are many, ranging from evolutionary psychology, social ontology and moral philosophy to mention only a few. Whereas on a superficial level the author presents "a detective story"14 on how morality came about; on a deeper level he lays out a sketch of the nature of morality. Rarely do philosophy books bear so many complex layers tied together in such an accessible way.

\footnotetext{
12 Ibid.

13 Buchanan and Powell (2018), 389.

14 Buchanan (2020), 231.

11 Buchanan and Powell (2018), 377.
} 


\section{2 §1 Environment Evolutionary Adaptations (EEA): from Flexible Cooperation to Super-Cooperation. The Rise of the Moral Mind}

According to an extensive interpretation of Darwin's theory of evolution, morality arises as a way of adaptation, that is, as a serving tool for reproductive fitness. ${ }^{15}$ One problem with this reading is that it cannot account for human cooperation with distant strangers, or for repulsion of unmotivated animal suffering. According to Buchanan, in order to make sense of these cases, it is necessary to consider the evolution of the moral mind as an improved form of cooperation. For Buchanan, the moral mind came about as a way of enhancing cooperation, but not as a form of cooperation itself; thus, it cannot be reduced to the latter.

In general, the moral mind expresses flexibility in response to different social environments. It is linked to emotional capacities and therefore it cannot be conceived as a "self-sufficient force". ${ }^{16}$ The moral mind (and its cognitive counterpart) is sensitive to the environment and therefore it "can result in fundamental moral changes". 17

Yet, what drove the change from cooperation to super-cooperation, that is, to morality as an enhanced form of cooperation?

Buchanan imagines a set of original conditions of environmental evolutionary adaptations (EEAs) that created pressures on natural selection criteria forging the moral mind. ${ }^{18}$ For Buchanan, it must be assumed that there has been $a$ plurality of EEA conditions that shaped the way the moral mind adapted itself to a series of group and environmental challenges. ${ }^{19}$ Flexible cooperation takes shape through the intergenerational acceptance of cumulative culture, that is, information, techniques and technologies. Morality is one core aspect of such cumulative culture since successful cooperation requires a subject to be a reliable partner and morality ensures this status-advancement. An interconnection has been established between the capacity for cumulative culture with (1) flexibility of moral sentiments, (2) the capacity for niche construction, and (3) the capacity for moral identity as the ability to convince others of the seriousness of the moral reasons we endorse.

The shift from human co-operators to super-co-operators was made possible by the gaining of a reproductive surplus condition in the niche construction that enabled a Great Uncoupling between adaptation and morality through "the loosening of the previously tight connection between what moralities are like and their ability to promote reproductive fitness". 20

Soon after reproductive surplus had been achieved, morality evolved independently as an autonomous resource for human cooperative reasoning. As noticed, for

\footnotetext{
15 "By facilitating cooperation within human groups-including cooperation that allowed a group to compete successfully with other groups". In, Buchanan (2020), 43.

16 Buchanan (2020), 156.

17 Ibid.

18 Buchanan (2020), 48-49.

19 Ibid.

20 Buchanan (2020), 23.
} 
Buchanan, morality is not all about cooperation, even if it came about in relation to this purpose. Whereas standard theories of cooperation and evolutionary advancements base their accounts on evolutionary adaptations for reproductive fitness, the idea of a Great Uncoupling considers that a fundamental change in the EEAs has occurred has transformed flexible cooperative subjects into super co-operators: cooperators with a moral concern.

The conditions in the EEAs included different groups with different immune stories responding to selective pressures by closing off one's group identity to another and by fighting outsiders (tribalism). ${ }^{21}$ Tribalism is a non-inclusive attitude separating Us and Them. It grounds the disruption of the possibility of inclusive moralities by pulling back societies to the stage of EEA and to its intragroup moral closure (cooperation only among likeminded/genetically similar members).

Yet, for Buchanan, we should also imagine the possibility for non-tribalistic responses to the EEA selective pressures. Indeed there seems to have been intergroup relations throughout the Pleistocene. ${ }^{22}$ The recognition of this fact plays in favour of a "special adaptive plasticity hypothesis". ${ }^{23}$ Here, adaptive flexibility allowed for weakly inclusive moral responses of cooperation with strangers in the EEAs (mutually advantageous interactions with strangers). For Buchanan, this blurrier scenario testifies that morality is not essentially tribalistic. Indeed, we can respond to selective pressures, which are either tribalistic or morally adaptive (and weakly cooperative/inclusive of strangers). Tribalistic responses are defused as long as cultural niche constructions create environments wherein threats are mitigated. ${ }^{24}$

To summarize: (1) even if in the EEA moralities are predominantly tribalistic, it does not follow that they are exclusively tribalistic; (2) we know that the moral mind is flexible regarding responses to strangers; (3) moral responses to inclusion of foreigners maintain mutual expectations of basic forms of reciprocity; (4) increasing inclusive societies reduced the reasons of differentiation between Us and Them; (5) cumulative culture became crucial for reproductive fitness-niche construction; (6) shallow inclusion changed moral responses and identity as well as paving the way for the First Great Expansion (invention of human rights) followed by the Second Great Expansion (recognition of moral worthiness of some animals); (7) cultural innovations were accompanied by technical innovations, reduction of epidemics etc. which strongly mitigated the harshness of the EEA conditions.

Since we can safely assume that the moral mind has not changed in the last 300 years, only cultural innovations are the relevant elements to consider for its definition. This is the significance of the Two Great Expansions with respect to the biological conditioning. ${ }^{25}$

\footnotetext{
21 Buchanan (2020), 69.

22 See also Sterelny (2012) quoted in Buchanan (2020), 113. The Pleistocene spans from 1 million to 100,000 years ago just before the Holocene, which spans from 100,000 to present day.

23 Buchanan (2020), 113.

24 Buchanan (2020), 120.

25 Buchanan (2020), 157.
} 


\section{$3 \$ 2$ Facilitating Conditions for Overcoming Tribalism: Moral Progress and the Institutionalization of Inclusive Moralities}

Once humans constructed niches, dragging them out from the harshness of the EEA, their open-ended moral thinking became possible on the base of 8 other conditions.

Some of these include the following: (1) widespread literacy, (2) considerable freedom of expression and literacy, (3) exposure to other societies with other ways of operating/living, (4) a developed culture of reason-giving, (5) no excessive pressures of moral conformity, (6) no excessive material and social burdens of innovation for moral innovators.

As Buchanan informs us, the Two Great Expansions are the result of "the progressive shift from shallowly inclusive (scattered cooperation with members of external groups but with no significant inclusion) to deeply inclusive moralities", and "should pay close attention to the capacity for critical, open-ended moral reasoning". 26

When humans achieved a good enough amount of reproductive surplus and advantage, their moral reasoning ceased to be informed by reproductive fitness. ${ }^{27}$ The process leading to the Two Great expansions became "cumulative [...and] create[d] niches in which they achieved sufficient surplus reproductive success [... then] the Great Uncoupling occurred". ${ }^{28}$

Which are the reasons for such uncoupling? For Buchanan, these are due to surplus reproductive advantage filled by moral reasons. The surplus reproductive advantage which occurred only in recent modern societies allowed humans to elevate their lives above the conditions of survival and orient moral thinking beyond reproductive advantage. With the Two Great Expansions, morality freed itself from the demands of reproductive fitness. ${ }^{29}$

According to Buchanan, even once the First Great Expansion occurred, tribalism was not irreversibly defeated. Tribalism indeed remains a perpetually "evolving" phenomenon as it is nowadays the new type of intra-societal tribalism that affects American democracy — and not only that!-by fuelling divisive ideologies. ${ }^{30}$

Ideologies can receive an evolutionary account in two respects: they are based on the same basic psychology that shaped moralities in the EEA and they represent an adaptation to the challenges faced by humans after the Neolithic revolution, as namely with competitions within large multi-ethnic and complex societies where violence is not an option. ${ }^{31}$ Ideologies are "[...] moralized evaluative maps of the social world that make group-based identities salient" 32 ; they "are product of cultural selection for what enables cooperation within a group under modern

\footnotetext{
26 Buchanan (2020), 143.

27 Ibid.

28 Buchanan (2020), 234.

29 Buchanan (2020), 125.

30 Buchanan (2020), 235.

31 Buchanan (2020), 214.

32 Buchanan (2020), 226.
} 
conditions". ${ }^{33}$ They also allow "competition against other groups within society" (ibid.); they can "erect formidable obstacles to overcoming the divisions between Us and Them" (ibid.). Even if ideologies can flourish only within cultures based on a process of reason-giving, they realize cooperation only within a small social subunit and therefore infuse of tribalism the entire society in which they operate.

So, ideology, as tribalism, can disrupt ordinary morality by "invoking the threat cues of the EEA and then connecting them to the existing predominant moral framework" ${ }^{34}$ A stark example is that of eugenics which, by pretending to be a science of improvement of a stock, it understands rather deterministically the relation between genes and behaviour. Eugenics is an instance of intrasocietal tribalistic morality. ${ }^{35}$

Buchanan asks: what are the conditions for the institutionalization of practical moral reason? ${ }^{36}$ Religions or philosophical doctrines have played an ambiguous role in permitting/facilitating the occurrence of the Two Great Expansions. Indeed, even if Christianity and Islam have justified wars of religion, they have also elaborated a conception of equal dignity before God. Yet, the type of moral change that is here considered is "widespread changes in moral ideas", ${ }^{37}$ something which bears significant changes in societies and institutions. As showed, this profound change occurred only recently, that is, in the last 300 years with the human rights revolution.

The First Great Expansion consists of recognizing equal dignity for all human beings (inclusive moralities): "we speak of human dignity, not just of the dignity of this or that group. We talk about human rights, not just the rights of Frenchmen or Americans etc. It's an expansion because it amounts to an enlargement of one's conception of who is a member of the primary moral community [...]". ${ }^{38}$ With the First Great Expansion, there occurred a transition from purely strategic to nonstrategic moral thinking (subject-centred understanding). This meant abandoning a mere "cooperation dogma" and accepting that moral reasoning is not just about facilitating cooperation, but rather about reason-giving. Understanding how moral consistency plays the role it does is to understand how it leads to the Two Great Expansions. Consistency in moral reasoning is to exhibit a more predictable behaviour than those who don't think morally. This means to be a more attractive subject for cooperation and, in turn, a reliable partner.

The Second Great Expansion consists of recognizing moral worthiness to some non-human beings (cats, dogs, bonobos etc.) "even if they don't have the high moral status that we humans do". ${ }^{39}$ Our repulsion for unmotivated cruelty against animals is a result of such second moral revolution. As Buchanan notes: whereas "The First Great Expansion enlarges the pool of humans considered to be first-class members

\footnotetext{
33 Buchanan (2020), 198.

34 Buchanan (2020), 195.

35 According to Buchanan, there are at least 6 hypotheses for the explanation of tribalistic regressions: $\mathrm{H} 1$ when people detect EEA threats they react in a tribalistic way, $\mathrm{H} 2$ the environment changes back to the EEA and tribalistic responses increase etc.

36 Buchanan (2020), 244.

37 Buchanan (2020), 160.

38 Buchanan (2020), 38.

39 Buchanan (2020), 40.
} 
of the moral community. The second enlarges the class of beings that count morally at all". 40

When we come to the present conditions, one should not forget that also in today's societies, even when one recognizes formal dignity, there might still be the possibility to discriminate internally if there are deeply divisive ideologies. ${ }^{41}$ Ideologies are cultural schemes of social interpretation that divide Us from Them in order to gain a competitive advantage for societal dominance. Institutional design and moral progress: large-scale moral change is the result of cultural accumulation and not of biological change! ${ }^{42}$

Finally, for Buchanan: "the institutional order in which large-scale moral progress is likely to come about through peaceful means will be - in broad terms - a liberal and at least minimally democratic order". ${ }^{43}$ This means that large portions of private property should be spread among people and no single entity should retain the control of all wealth. Yet, this does not amount to saying that laissez-faire capitalism should be tolerated since this would be "a moral disaster" ${ }^{44}$ So, markets should be regulated within the framework of a liberal democracy where an open-ended moral critical thinking highlights the inconsistencies in public moral reasoning.

What are the conclusions Buchanan draws from this entire enquiry? Democracy is the only publicly available resource we have invented so far to contain "intrasocietal tribalism in the competition among adaptations for competition among groups within society". 45 Thus, as Buchanan concludes, we should retain a sense of hope for the future. Even though current political scenarios lean more towards moral tribalism, we should not forget that: "We've gotten beyond tribalism before; perhaps we can learn to escape the new forms it's now taking". 46

I have intentionally separated a selection of the arguments in Buchanan's book from their assessment. Along the third section, therefore, I examine some of Buchanan's central tenets on moral evolutionary theory. I will focus on (1) the overcoming of the notion of We-group as a closed social system; (2) I will critically engage in the discussion of the continuity vs the uncoupling thesis, from which the normative force of morality derives. Next, (3) I will conclude by suggesting a possible Third Great Expansion. Here, I suggest that the environment should be considered as yet another source of moral obligation in addition to the humans and the animals identified by the Two Great Expansions. The inclusion of the environment links more closely competitive and collaborative standards, such as the competition for the fittest with cooperation in safeguarding the conditions of human survival.

\footnotetext{
40 Ibid.

41 Buchanan (2020), 245.

42 Buchanan (2020), 236.

43 Buchanan (2020), 149.

44 Buchanan (2020), 150.

45 Buchanan (2020), 244.

46 Buchanan (2020), 249.
} 
Bearing all this in mind, one could proceed at a partial reframing of Buchanan's socio-ethnological oppositional categories of the Us vs Them divide.

\section{$4 \S 3$ Buchanan's Evolutionary Morality: a Tale of Two Stories?}

Buchanan's views are that at some point of human history, due to reproductive surplus, in the moral mind, there occurred a process of uncoupling between the maxim of selection of the fittest vs the principle of morality as a system of fair cooperation among equals. I believe that this is a distinctive idea on how morality has emerged. Yet, it requires to be investigated more.

Let me present some reasons. First, I consider that Buchanan holds too strict an opposition between the intergroup psychological mindset and the accompanying cultural and ideological superstructures: the Us/Them dichotomy and its accompanying tribalism. Consequently, the concession Buchanan makes to intergroup relations is only ephemeral and does not really modify his main paleo-sociological thesis. With reference to ethnological studies, I aim to show how the Us/Them divide Buchanan discusses is a culturally mediated type of relation (not a kind of category of natural psychology) which incorporates a loose morality (preferences for group members with some exceptions, i.e. for reproductive purposes). It follows that inner-outer group relations are sensitive to a plethora of cultural and reproductive transcriptions and cannot be reduced to an either all-exclusive or all-inclusive type of morality. Buchanan's idea of a social discontinuity between pre-human rights and post-human rights group moralities oversimplifies a complex intercultural social relation. The suggestion is that from a group perspective, human rights morality is rather a hyper inclusive expansion of already partially inclusive group moralities. The difference is on the justifying reasons that lead to such moral change.

Second, I investigate the significance of morality in Buchanan's terms and ask in which terms the conditions for the rise of the moral mind inform us of the evolutionary significance of the uncoupling thesis. The result is a milder understanding of the normative gap between pre-uncoupling and post-uncoupling moralities. All in all, this point aims to provide an insight into what can evolutionary theory tell us with regard to morality. ${ }^{47}$

Let me start with the first point. For a good number of anthropologists, the opposition between "I-Us-Others" is a persistently ethnocentric false image. The origin of such cultural scheme, opposing We-groups to Others, is Sumner's conception of "folkways" as "natural" social arrangements. ${ }^{48}$ The We-groups are in Summer a primitive society (as the term "primitive" was a customary definition of that time) of small, scattered groups. They introduce a distinction between:

\footnotetext{
47 For a discussion of this point, see my editorial in this issue.

48 " $[\ldots]$ in all ages and stages of culture, is primarily controlled by a vast mass of folkways handed down from the earliest existence of the race.” In, Sumner (1979), 4.
} 
the we-group, or in-group, and everybody else, or the others-group, outgroups. The insiders of a We-group are in a relation of peace, order, law, government and industry to each other. Their relation to all outsiders, or othersgroups, is one of war and plunder, except so far as agreements have modified it. (Sumner 1979, 12)

A few years earlier, in Germany, Tönnies had published his most famous study Gemeinschaft und Gesellschaft [1887] 2001, ${ }^{49}$ where he drew a distinction between community (Gemeinschaft), usually a small group-association based on shared values and privacy, and society (Gesellschaft), a more articulate group of variously interconnected individuals. For Tönnies, whereas the community is characterized by a strong form of self-identification in a We-group of traditions opposed to the outer Other, the society is characterized by a "nebeneinander" (a proximity relation) which leaves some spaces among individuals, so to say. This is the terrain of individualism in modern societies. ${ }^{50}$

These long-lasting hyper simplifications of societal "infra-" and "inter-" relations have been effectively criticized by Tylor in his definition of culture and cultural interconnections: "savage tribes must have had plainly before their minds the simple practical alternative between marrying-out and being killed out". ${ }^{51}$ Establishing extra-group marriages was for primitive tribes a way to make a cost-benefits calculus and to avoid killing and being killed. Tylor's remarks countervail the process of "othering" as the mainstream reading of the identity construction of savage social groups in that it exemplifies the cohabitation-not the mere coexistence-of the groups. ${ }^{52}$

Recent anthropological studies have shown that inner-outer group relations always exhibit deeper cultural meaning than is usually considered. The American anthropologist R. Grinker has illustrated what a complex othering relation exists between the Lese farmers and the Efe hunters of the Ituri forest in the Democratic Republic of the Congo. ${ }^{53}$ Even if the Lese consider the Efe similar to monkeys, they engage in reciprocal forms of cohabitation with mutual marriages and children raising. Most importantly, the Efe are assigned by the Lese the role of seeking the kunda (the evil) within their villages. How should this practice be interpreted given the de-humanizing consideration that the Lese bear for the Efe? The answer is subtle but crucial. It relies on the creation of an "inner-symbiotic" 54 inclusion of the other in Lese's society. Why so? The psychology behind this is that in order to defeat recursively the evil that resides within us (in our societies), we must bring in an external entity - the Efe-the inhabitants of the forest. The Lese are culturally aware that the formation of intrasocietal evil (jealousy, mutual distrust, social unbalances etc.) is

\footnotetext{
49 Tönnies [1887] (2001).

50 For an overview analysis of these concepts, see Remotti (2021) (in press).

51 Tylor (1889), 267.

52 See Remotti (2021) (in press), 12. On this point, see also de Scola (2013) and Corradetti and Spreafico (2005).

53 Grinker (1990), 111-130. This ethnological case is discussed in Remotti (2021) (in press), $17 \mathrm{ff}$.

54 See Remotti (2021) (in press), 17 ff.
} 
the unavoidable outcome of closed societies. We cannot take away the evil of which we are victims by ourselves. We need instead others to do it for us. Only by allowing a radical other into our societies can we identify and eradicate the evil of our We-group. This explains why the Lese and the Efe have been cohabiting in a form of mutual dependence and repulsion. According to this example, tribalism is an inner feature of any society which calls for foreign inclusions and healing. Tribalism is also an external attitude of a We-group towards a different Other, but neither of these two relations are mutually independent, nor should we treat them so. Whereas for the Lese and the Efe such space is regulated by rites and religious creeds, for us today this inner-outer jurisdictional space is regulated by the discourse of human rights. There is a difference though between these two moral/societal regulatory systems, but this is only a difference in the degree of societal inclusion of the other. In one case, it is a single collective other, whereas in the other case it is a generalized collective other (humankind in virtue of its "inherent dignity"). Differences are in the cultural niche constructions and in the way in which these provide selective criteria for cooperation and subsistence: not in a sort of natural psychology discriminating between genetically related vs non-genetically related groups.

Regarding the second point, Buchanan speaks of morality both for divisive moralities of the EEAs and for inclusive and super inclusive moralities of the Two Great Expansions. Does this mean that the nature of morality is only one even when it shifts from less cooperative to more cooperative moralities? If so, it wouldn't be clear why the Two Great Expansions prompt an uncoupling process between fitness selection and morality as cooperation. Rather, could it be the case that moral shifts imply simply a modification of fitness selection criteria with regard to the reasons for moral justification, turning the latter into universal and hyper inclusive?

Buchanan's uncoupling thesis is connected to the idea that morality, in the human rights expansion, is deeply different from psychological altruism, a natural attitude deliberately benefiting others. It is also different from biological altruism, a behaviour increasing others' reproductive fitness (through genetic transmission to future generations). The uncoupling thesis aims at stressing precisely this radical discontinuity; yet, this appears as missing the link with what I might call as the natural preconditions for the rise of universal moralities.

Buchanan rightly claims that morality in general originates in adaptive conditions and that it is only with reproductive surplus that the First Great Expansion (human rights) and a radical innovation arises, detaching the reasons for the justification of moral principles from selective contexts.

This account offers support to the author's reading of human rights expansion in morality but in addition it suggests a reformative, rather than a revolutionary, change between the pre- and the post-phase of the First Great Expansion. The remark is that some form of inclusive moral concepts had to be already available in the EEA's conditions as a kind of (small) intergroup cooperation. It follows that moral advancements moved from biological/psychological altruism to the exchange of moral reasons. If this is the case, then, one should see morality as arising from a process of bootstrapping of the moral mind and starting from natural conditions of cooperation. As in the cognitive domain, there is not a stage of "no thought" followed by a stage of "thought" (according to Tomasello's account of the birth of collective 
intentionality and morality), ${ }^{55}$ one might think by analogy that morality does not proceed from a condition of non-morality to a condition of full morality. In this respect, evolutionary theory provides us with the pro-social skills and moral sentiments that only autonomously conducted normative reasoning would fill-in (by presenting ethically justified principles).

So, the challenging question to rebut is: if it not the case that there occurred something truly distinctive about morality (as the capacity to justify our normative principles independently from fitness considerations), couldn't it be the case that morality is all about inclusive fitness $?^{56}$ Or, about selective pressures for reciprocal altruism $?^{57}$ Or, finally, about group selection $?^{58}$

These competitive accounts do indeed offer an explanation for cooperative behaviour-on the base of either biological or psychological forms of altruism-but they do not conceive of moral reasoning as an autonomous capacity. In this respect, these accounts are more compatible with Darwin's consideration of ecological settings for animal moral frameworks, ${ }^{59}$ but not with Buchanan's idea of an evolutionary uncoupling allowing moral reasoning. This route of reasoning, if expanded, would justify a plurality of lines of conduct eventually applying also to humans living along different ecological habitats.

All in all, it would be interesting to learn more about the role Buchanan assigns to the autonomy vs ecological dependence of morality, and ultimately how he switches between accounts based on descriptive evolutionary ethics (empirical accounts of the origins of moral feelings, capacities for moral judgments, motivations based on certain moral feelings etc. and accounts of "moral evolution"), prescriptive evolutionary ethics (reference to evolutionary theory to support/undermine normative claims such as the idea of human and non-human dignity) and, finally, evolutionary metaethics.

Does Buchanan endorse cognitivist or non-cognitivist semantics, given that the former appears to be matched to the First Great Expansion, but only the latter to the Second Great Expansion?

Does he maintain the idea that we came to accept human dignity as a way to justify the ability to recognize moral truth through natural selection?

Have we come to believe in certain moral concepts because of certain moral truths selected by cultural niche constructions? If this were the case, then, such view would not square with the idea of morality as a reason giving enterprise, nor with the type of institutionalization of the moral reason that is suggested to be at play in democracies. But if the answer is one of a non-cognitivist explanation of morality, then, Buchanan's account seems rather compatible with an expressivist metaethical

\footnotetext{
55 "Many philosophers reacted by simply defining away the problem: thinking is a process that takes place in, and only in, the medium of language, and so other animal species cannot think by definition (the most prominent modern proponents being Davidson [2001] and Brandom [1994]). Recent research on great ape cognition and thinking, such as that reviewed here, should already be undermining this 'radical discontinuity' view". In, Tomasello (2014), 149.

56 Hamilton (1964a and 1964b).

57 Trivers (1971), Maynard Smith (1982), Axelrod (1984).

58 Sober and Wilson (1998).

59 Darwin [1871] (1981), 73.
} 
view that connects selection pressures with a non-cognitive acceptance of norms of guidance. ${ }^{60}$ As a result, compliance to normative standards as a form of adaptation to social coordination and normative stabilization would become possible and norm acceptance would remain a natural non-cognitive fact.

I conclude this reflection by referring again to what I mentioned earlier in terms of an expanded horizon of moral evolutionary thinking which Buchanan might incorporate in his views: the environment. We are now back to considering nature as a source of moral reasoning and as an enabling condition for adaptive evolution. This insight would certainly fulfil Tomasello's condition of interdependence as a prerequisite for the evolutionary emergence of a moral framework in the midst of a new and enlarged vision. ${ }^{61}$ Current ecological turns in philosophical reflection, something often referred to in terms of the Anthropocene, informs us of two elements: that the We-group fate is linked to the human fate in general and that the human fate is linked to the preservation of a healthy environment.

A possible Third Great Expansion would reframe the other Two within one single human/animal/ecological circle of interdependency. This might suggest a possible way forward to Buchanan's detective story. It would also reconsider some of the basic sociological assumptions, as the opposition between Us-Them, Humans-NonHumans, the Environment and so on in an all-encompassing view.

Saving nature is to save humans. Today, after wild decades of hyper industrialization, growing consumerism and exploitation of natural resources, we have become finally aware that there is no escape from tribalism if we fail to adopt a normative standard for ecological respect. Sensitivity to species extinction goes hand in hand with considerations of ecological life cycles, water, air, soil. In evolutionary terms, our moral fate and human subsistence are strictly dependent on the type of interrelation we build with nature.

Funding Open access funding provided by Università degli Studi di Roma Tor Vergata within the CRUICARE Agreement.

Open Access This article is licensed under a Creative Commons Attribution 4.0 International License, which permits use, sharing, adaptation, distribution and reproduction in any medium or format, as long as you give appropriate credit to the original author(s) and the source, provide a link to the Creative Commons licence, and indicate if changes were made. The images or other third party material in this article are included in the article's Creative Commons licence, unless indicated otherwise in a credit line to the material. If material is not included in the article's Creative Commons licence and your intended use is not permitted by statutory regulation or exceeds the permitted use, you will need to obtain permission directly from the copyright holder. To view a copy of this licence, visit http://creativecommons.org/licen ses/by/4.0/.

\section{References}

Axelrod A (1984) The evolution of cooperation. Basic Books, New York

Buchanan A, Powell R (2018) The evolution of moral progress. A biocultural theory. Oxford University Press, Oxford

\footnotetext{
60 Kitcher (2006).

61 Tomasello (2016), Ch.5. See the editorial in this issue.
} 
Buchanan A (2020) Our moral fate Evolution and the escape from tribalism. MIT Press, Cambridge and London

Campbell R (1996) Can biology make ethics objective? Biol Philos 11:21-31

Corradetti C, Spreafico A (2005) Oltre lo "scontro di civiltà": compatibilità culturale e caso islamico, Fondazione A. Olivetti, Roma

Dawkins R (2016) The extended selfish gene, 3rd edn. Oxford University Press, Oxford

Darwin C [1859] (2008) The origin of species, Oxford World's Classic. Oxford: Oxford University Press

Darwin C [1871] (1981) The descent of man and selection in relation to sex. London: John Murray. First edition reprint. Princeton: Princeton University Press

de Scola P (2013) Beyond nature and culture. The University of Chicago Press, Chicago and London

Grinker R (1990) Images of denigration: Structuring inequality between foragers and farmers in the Ituri Forest, Zaire. Am Ethnol 17(1):111-130

Grinker R (1994) Houses in the rainforest. Ethnicity and inequality among the farmers and foragers in Central Africa. University of California Press, Berkeley

Hamilton WD (1964a) The genetical evolution of social behaviour I. J TheorBiol 7(1):1-16

Hamilton WD (1964b) The genetical evolution of social behaviour II. J TheorBiol 7(1):17-52

Joyce R (2006) The evolution of morality. The MIT Press, Cambridge and London

Kitcher P (2006) Biology and ethics. In: Copp D (ed) The Oxford handbook of ethical theory. Oxford University Press, Oxford, pp 163-185

Laland KN (2017) Darwin's unfinished symphony. How culture made the human mind. Princeton University Press, Princeton and Oxford

Maynard Smith J (1982) Evolution and the theory of games. Cambridge University Press, Cambridge

Odling-Smee FJ, Laland KN, Feldman MW (2003) Niche construction. The neglected process in evolution. Princeton University Press, Princeton and Oxford

Remotti F (2021) "Coexist and convivere. Between similarities and differences", in, Facci S., Giuriati G. (eds) Music of the twenty-first century diasporas: Research and methods, Venezia, Fondazione Luigi Cini

Sober E, Wilson DS (1998) Unto others: The evolution and psychology of unselfish behaviour. Harvard University Press, Cambridge

Sterelny K (2003) Thought in a hostile world. The evolution of human cognition. Blackwell, London

Sterelny K (2012) The evolved apprentice: How evolution made humans unique. MIT Press, Cambridge

Sumner WG (1979) Folkways a study of the sociological importance of usages, manners, customs. Arno Press, New York

Richards RJ (1986) A defense of evolutionary ethics. Biol Philos 1:265-293

Tomasello M (1999) The cultural origins of human cognition. Harvard University Press, Cambridge and London

Tomasello M (2014) A natural history of human thinking, Harvard University Press. Cambridge Mass, London

Tomasello M (2016) A natural history of human morality. Cambridge University Press, Cambridge and London

Tomasello M (2019) Becoming human. A theory of ontogeny. Harvard University Press, Cambridge and London

Tönnies F (2001) Community and civil society. Cambridge University Press, Cambridge

Trivers R (1971) The evolution of reciprocal altruism. Q R Biol 46:35-57

Tylor BE (1889) Applied to laws of marriage and descent. Journal of the Royal Anthropological Institute XVIII: 245-269

Publisher's Note Springer Nature remains neutral with regard to jurisdictional claims in published maps and institutional affiliations. 